\title{
Implications of moderate altitude training for sea-level endurance in elite distance runners
}

Accepted: 19 March 1998

\begin{abstract}
Elite distance runners participated in one of two studies designed to investigate the effects of moderate altitude training (inspiratory partial pressure of oxygen $\approx 115-125 \mathrm{mmHg}$ ) on submaximal, maximal and supramaximal exercise performance following return to sea-level. Study 1 (New Mexico, USA) involved 14 subjects who were assigned to a 4-week altitude training camp (1500-2000 m) whilst 9 performance-matched subjects continued with an identical training programme at sea-level $(\mathrm{CON})$. Ten EXP subjects who trained at $1640 \mathrm{~m}$ and 19 CON subjects also participated in study 2 (Krugersdorp, South Africa). Selected metabolic and cardiorespiratory parameters were determined with the subjects at rest and during exercise 21 days prior to (PRE) and 10 and 20 days following their return to sealevel (POST). Whole blood lactate decreased by $23 \%$ $(P<0.05$ vs PRE) during submaximal exercise in the EXP group only after 20 days at sea-level (study 1). However, the lactate threshold and other measures of running economy remained unchanged. Similarly, supramaximal performance during a standardised track session did not change. Study 2 demonstrated that hypoxia per se did not alter performance. In contrast, in the EXP group supramaximal running velocity decreased by $2 \%(P<0.05)$ after 20 days at sea-level.
\end{abstract}

D.M. Bailey $(\bowtie) \cdot$ B. Davies

Field of Health and Exercise Science,

School of Applied Sciences,

University of Glamorgan, Pontypridd, South Wales, UK

L. Romer

British Olympic Medical Centre,

Northwick Park Hospital,

Harrow, Middlesex, UK

L. Castell · E. Newsholme

Cellular Nutrition Research Group,

Department of Biochemistry,

University of Oxford, UK

G. Gandy

Loughborough University,

Loughborough, Leicestershire, UK
Both studies were characterised by a $50 \%$ increase in the frequency of upper respiratory and gastrointestinal tract infections during the altitude sojourns, and two male subjects were diagnosed with infectious mononucleosis following their return to sea-level (study 1). Group mean plasma glutamine concentrations at rest decreased by $19 \%$ or $143(74) \mu \mathrm{M}(P<0.001)$ after 3 weeks at altitude, which may have been implicated in the increased incidence of infectious illness.

Key words Hypobaric hypoxia Infectious mononucleosis · Plasma glutamine · Immunosuppression

\section{Introduction}

Acclimatisation to a reduced inspiratory partial pressure of oxygen $\left(P_{\mathrm{I}} \mathrm{O}_{2}\right)$ initiates metabolic and cardiorespiratory adaptations that influence oxygen transport and utilisation. Some adaptations may facilitate endurance performance, whereas others are less beneficial. Although equivocal, human studies have demonstrated that either hypobaric or normobaric hypoxia per se is responsible for increases in blood haemoglobin $(\mathrm{Hb})$ concentration (Berglund 1992), muscle mitochondrial volume, capillary supply (Desplanches et al. 1993), aerobic enzyme activities and myoglobin concentration (Terrados et al. 1990), 2,3-diphosphoglycerate (Mairbaurl et al. 1986), rate of free fatty acid mobilisation (Young et al. 1982) or an elevated blood buffering capacity (Favier et al. 1995). Altitude acclimatisation improves physical performance at altitude (Pugh 1967; Maher et al. 1974), but the effects on sea-level performance are less clear. Since the 1950's, 64 out of 91 studies on the effects of altitude training on sea-level endurance performance have been conducted without a performance-matched control group trained in normoxia, and of the 15 controlled investigations, only 4 have reported performance-enhancing benefits (Bailey and Davies 1997). 
Hypobaric hypoxia decreases training intensity, and this may induce a detraining response (Levine and StrayGundersen 1997), as demonstrated in the elite athlete at altitudes as low as $610 \mathrm{~m}$ above sea-level (Gore et al. 1996). Levine and Stray-Gundersen (1997) demonstrated the synergistic effects of altitude acclimatisation and endurance training as a means of potentiating sea-level endurance performance in a "live-high, train-low" approach. However, there is evidence which challenges the benefits of altitude training. Oxygen transport, determined as a product of blood flow and arterial oxygen concentration (flow $\times C_{\mathrm{a}} \mathrm{O}_{2}$ ) is regulated in response to changes in arterial partial pressure of oxygen (Welch 1987). Wolfel et al. (1996) investigated systemic oxygen transport at an ambient partial pressure of oxygen $\left(\mathrm{PO}_{2}\right)$ of $97 \mathrm{mmHg}$ and established that despite the increase in $C_{\mathrm{a}} \mathrm{O}_{2}$ due to an increased $\mathrm{Hb}$ concentration, oxygen transport was unaffected due to a reduction in blood flow caused by sympathetically mediated local and/or systemic vasoconstriction. A decrease in muscle perfusion persists following return to sea-level. Using ${ }^{133} \mathrm{Xe}$ it has been shown that blood flow to the vastus lateralis muscle decreases by as much as $39 \%$ during submaximal exercise after a 3-month expedition to $8,398 \mathrm{~m}$ (Boutellier et al. 1982).

Both in vivo and in vitro evidence suggests that hypobaric hypoxia decreases immunoreactivity, specifically by suppressing T-cell-mediated immunity (Meehan 1987, 1988). Oxidative damage mediated by free radicals also increases at altitude (Simon-Schnass 1990; Vasankari et al. 1997) which has implications for membrane integrity and energy metabolism. In addition to the potentially immunosuppressive effects of high-volume intense physical exercise (Nieman 1996), the additional stress of a decreased $P_{\mathrm{I}} \mathrm{O}_{2}$ may challenge both the health and fitness of the elite competitor.

Two studies were designed to elucidate the mechanisms that regulate physiological indices of submaximal, maximal and supramaximal exercise performance following a sojourn to altitude in a homogenous group of elite distance runners.

\section{Methods}

Subjects

Fifty two British National distance runners (800-5,000 m specialists) volunteered and gave their informed consent for two altitude training studies which had been approved by the British Olympic Association and the British Athletic Federation (Table 1). All subjects were taking oral iron supplements $(200 \mathrm{mg}$ of ferrous sulphate $\cdot$ day $^{-1}$ ).

Two investigations were conducted at the same time of year and at similar altitudes $\left(1500-2000 \mathrm{~m}\right.$ above sea-level, $P_{\mathrm{I}} \mathrm{O}_{2}=115$ $125 \mathrm{mmHg}$ ). The first study investigated the responses to submaximal $\left[<\right.$ maximal oxygen uptake $\left.\left(\dot{V} \mathrm{O}_{2 \max }\right)\right]$ and supramaximal $\left(>\dot{V} \mathrm{O}_{2 \max }\right.$ ) exercise following 4 weeks of endurance training at Albuquerque, New Mexico (1500-2000 m). The second study investigated responses to maximal and supramaximal exercise following 4 weeks of similar training at Krugersdorp, South Africa $(1640 \mathrm{~m})$

Study 1: Submaximal laboratory measurements and procedures

Each subject performed two standardised treadmill runs to control for the effects of habituation on exercise performance. Sixteen male and seven female subjects subsequently performed a discontinuous incremental treadmill test in a temperature-controlled laboratory set at $21 \pm 1{ }^{\circ} \mathrm{C}$. The test consisted of five incremental stages each of $4 \mathrm{~min}$ in duration and separated by $30 \mathrm{~s}$ for the collection of an earlobe blood sample for the determination of the lactate threshold $\left(\theta\left[\mathrm{La}^{-}\right]_{\mathrm{B}}\right)$, according to the method of Cheng et al. (1992). Running velocity $\left(\mathrm{m} \cdot \mathrm{s}^{-1}\right)$ at a fixed whole blood lactate concentration $\left(\left[\mathrm{La}^{-}\right]_{\mathrm{B}}\right)$ of 2 and $4 \mathrm{mmol} \cdot \mathrm{l}^{-1}$ was interpolated by fitting an exponential equation to each subject's lactate-velocity curve. Treadmill velocity increments were calculated to represent between 70 and $110 \%$ of the subjects' $10-\mathrm{km}$ personal best running times on the road and ranged between 3.56 and $5.86 \mathrm{~m} \cdot \mathrm{s}^{-1}$ for the male athletes and 3.19 to $5.06 \mathrm{~m} \cdot \mathrm{s}^{-1}$ for the females. The subjects were subsequently assigned to two groups: 14 subjects travelled to an altitude training camp based at New Mexico $\left(\mathrm{EXP}_{\mathrm{SUB}}\right)$ whilst 9 subjects continued with their normal training programme at sealevel in the UK $\left(\mathrm{CON}_{\mathrm{SUB}}\right)$. Each subject performed the test 3 weeks prior to $\left(\mathrm{PRE}_{\mathrm{SUB}}\right)$ and 3 weeks following their return from altitude $\left(\mathrm{POST}_{\mathrm{SUB}}\right)$.

Study 2 Maximal laboratory measurements and procedures

Twenty two male and seven female subjects $(n=29)$ performed an incremental treadmill test to exhaustion according to Taylor et al. (1955) for the determination of $\dot{V} \mathrm{O}_{2 \max }$. This was preceded by a 3min recovery walk on the level at $1.39 \mathrm{~m} \cdot \mathrm{s}^{-1}$ (REC). Subjects were

Table 1 Anthropometric and dietary data at sea-level. (PRE EXP $S U B$ Pre-altitude experimental submaximal exercise group, PRE $C O N_{S U B}$ pre-altitude control submaximal exercise group, $P R E E X P_{M A X}$ pre-altitude experimental maximal exercise group, $P R E C O N_{M A X}$ pre-altitude control maximal exercise group, $F V C$ forced vital capacity, $C H O$ carbohydrate intake, Cal intake daily calorific intake)

\begin{tabular}{|c|c|c|c|c|}
\hline & \multicolumn{2}{|l|}{ New Mexico } & \multicolumn{2}{|l|}{ South Africa } \\
\hline Age (years) & 24 & $25 \quad$ (4) & $22 \quad(4)$ & $24 \quad(2)$ \\
\hline Body mass (kg) & $62.0(8.7)$ & $60.9(6.0)$ & $68.6(7.3)$ & $64.2(6.6)$ \\
\hline Stature (m) & $1.75(0.11)$ & $1.73(0.06)$ & $1.79(0.07)$ & $1.75(0.08)$ \\
\hline $\operatorname{FVC}\left(1 \cdot \min ^{-1}\right)$ & 4.81 (0.99) & $4.90(0.77)$ & $5.40(0.91)$ & $5.07(0.71)$ \\
\hline Cal intake $(\mathrm{J})$ & $12.461(2.011)$ & $11.032(2.401)$ & $12.796(2.757)$ & $12.654(3.767)$ \\
\hline
\end{tabular}


assigned to 2 groups: 10 subjects travelled to a 4-week altitude training camp in South Africa $\left(\mathrm{EXP}_{\mathrm{MAX}}\right)$, and the remaining 19 subjects continued with their normal training programme at sealevel $\left(\mathrm{CON}_{\mathrm{MAX}}\right)$. Each subject performed the test 3 weeks prior to the altitude sojourn (PRE $\mathrm{PAX}_{\mathrm{X}}$ ), after 19 days at altitude in the EXP $_{\text {MAX }}$ group only (ALT $T_{\text {MAX }}$ ), and 10 and 20 days following return to sea-level (POST MAX1 $_{\text {and }}$ POST $_{\text {MAX2 }}$, respectively).

\section{Supramaximal measurements and procedures}

Both studies incorporated a track test 3 weeks pre- and 3 weeks post-altitude sojourn and between weeks 2 and 3 at the respective altitude training camps. Subjects were instructed to perform four repetitions of $1000 \mathrm{~m}$ on a tartan track, separated by a 2min recovery walk at the fastest and most consistent velocity possible.

\section{Cardiorespiratory measurements}

Flow loop spirometry (Cosmed Kit, Cosmed SRL, Rome, Italy) was used for the determination of forced vital capacity, maximum voluntary ventilation and mid-expiratory flow rates. Timed measurements of expired air were analysed using an on-line gas analysis system, (MedGraphics Cardiopulmonary Exercise Systems CPX/ D, Cardiokinetics, UK) which was validated with an off-line reference system. A bipolar three-lead electrocardiogram (ECG) was displayed during exercise (Rigel 304, Graseby Medical, London). Heart rates (HR) during the track sessions were recorded via ECG calibrated bipolar telemetry (Vantage, Polar Electro, Oy, Finland). Ratings of perceived exertion were also monitored during the exercise tests (Borg 1973).

\section{Haematological measurements}

Arterialised capillary blood samples $(20 \mu \mathrm{l})$ were sampled from the right earlobe for the subsequent determination of $\left[\mathrm{La}^{-}\right]_{\mathrm{B}}$ using an automated analyser (Analox PLM5 Champion, London, UK). Serum urea was measured using a portable reflectance photometer (Refletron, Manheim Boehringer, Germany). Venous blood samples were collected after a 12 -h overnight fast and $48 \mathrm{~h}$ following exercise by antecubital venupuncture, $30 \mathrm{~min}$ after the subject had assumed a seated position to control for plasma volume shifts (Pronk 1993). Blood samples were analysed for a full blood count, serum ferritin, serum vitamin $B_{12}$, red cell folate, plasma iron and transferrin. Plasma was frozen and, following deproteinisation, was subsequently analysed for glutamine via an enzymatic method (Windmueller and Spaeth 1974). Briefly, glutamine was hydrolysed with asparaginase to produce glutamate. This was hydrolysed to $\alpha$-ketoglutarate with glutamate dehydrogenase, and the rate of oxidation (i.e. formation of NADH) was detected spectrophotometrically at $340 \mathrm{~nm}$ (Gilford, Stasar III, UK).

\section{Dietary analysis}

All subjects completed a self-reporting 3-day dietary analysis 3 weeks prior to the altitude training camp, which was analysed using a computer program (Compeat, UK).

\section{Illness}

Each subject in study 2 was issued with a 7-day questionnaire prior to sea-level laboratory testing and on a daily basis during the training period at altitude or at sea-level. Experience of gastrointestinal and/or upper respiratory tract infections, which included persistent coughing, sore throat, cold/influenza, fever, diarrhoea and vomiting were recorded on a daily basis by the subjects.

\section{Training programme}

Subjects recorded total weekly running distances and their corresponding HR 1 week prior to PRE and POST testing and during weeks $1-4$ at altitude. These distances were divided into track (HR $\approx 170-185$ beats $\left.\cdot \mathrm{min}^{-1}\right)$ and steady-state $(\mathrm{HR} \approx 140-160$ beats $\mathrm{min}^{-1}$ ) running sessions. All subjects were instructed to continue with their current training programme throughout the duration of the study. The EXP groups performed altitude training sessions at the same relative exercise intensity as the training conducted at sealevel (i.e. same HR) with the use of ECG-calibrated bipolar telemetry.

\section{Statistical analyses}

The mean sample size required for the detection of a statistically significant difference as a function of the treatment effect (hypobaric hypoxia) was determined for a variety of dependent variables, according to Altman (1980). Data were analysed using both parametric and non-parametric statistics following application of the Shapiro-Wilk W test for Normality (Altman 1991) and the Normal P-P Plot (Kinnear and Gray 1994). Within-group comparisons were analysed using a paired-samples $t$-test and a onefactor repeated measures analysis of variance (ANOVA). The Wilcoxon Matched-Pairs Signed-Ranks test and the Friedman test served as the non-parametric equivalents. Between-group comparisons were conducted using a $t$-test for independent samples or the Mann-Whitney U test. Statistical significance was defined at the $P<0.05$ level for all two-tailed tests, and values are reported as means (SD).

\section{Results}

\section{Resting haematologic and cardiorespiratory data}

The confounding effects of hypohydration on the haemodynamic and cardiorespiratory responses to hypobaric hypoxia were minimal. Fluid intake at sea-level and altitude ranged from 2.5 to $10.11 \cdot$ day $^{-1}$ and, as a consequence, the EXP group appeared to be in a euhydrated state. Resting urine osmolalities did not change during study 2. Mean osmolalities at sea-level and altitude ranged from 386 to $746 \mathrm{mosmol} \cdot \mathrm{kg}^{-1}$ for the EXP group and from 614 to $761 \mathrm{mosmol} \cdot \mathrm{kg}^{-1}$ for the CON group. Chronic hypobaric hypoxia had no effect on resting $\mathrm{Hb}$ concentration, packed cell volume or resting serum urea concentration (Tables 2 and 3). Haematinic data remained stable throughout the South Africa study (Table 4). Group mean serum ferritin concentrations were low and four subjects in the EXP group and six subjects in the CON group were iron deficient (serum ferritin concentration $<35 \mathrm{ng} \cdot \mathrm{ml}^{-1}$ ) despite daily iron supplementation. Resting HR decreased during and 10 days following the South Africa sojourn $(P<0.01$ and $P<0.05$, respectively vs PRE). Mean arterial blood pressure remained stable throughout the studies. Lung function did not change at altitude despite a $20 \%$ reduction in air density.

The frequency of upper respiratory tract and/or gastrointestinal tract infections increased markedly during both altitude sojourns (Fig. 1). In contrast, there were no reports of infectious illnesses for subjects in the 
Table 2 Resting cardiorespiratory and haematologic data at sealevel and altitude. (PRE Pre-altitude test, $A L T$ altitude test, POST post-altitude test, $E X P_{S U B}$ experimental submaximal exercise group, $C O N_{S U B}$ control submaximal exercise group, $\mathrm{Hb}$ hae- moglobin, $P C V$ packed cell volume, $H R$ heart rate, $M A B P$ mean arterial blood pressure, $F E F_{25-75 \%}$, mid-expiratory flow rate, $M V V$ maximal voluntary ventilation)

\begin{tabular}{|c|c|c|c|c|c|}
\hline & \multicolumn{3}{|l|}{$\mathrm{EXP}_{\mathrm{SUB}}$} & \multicolumn{2}{|l|}{$\mathrm{CON}_{\mathrm{SUB}}$} \\
\hline Serum urea $\left(\mathrm{mmol} \cdot \mathrm{l}^{-1}\right)$ & $5.63(1.79)$ & $6.57(1.26)$ & $6.01(1.56)$ & $4.89(1.26)$ & $5.52(1.90)$ \\
\hline $\mathrm{Hb}\left(\mathrm{g} \cdot \mathrm{dl}^{-1}\right)$ & $14.5(1.7)$ & $15.3(1.2)$ & $15.1(1.5)$ & $15.2(1.3)$ & $15.1(1.3)$ \\
\hline $\operatorname{PCV}\left(1 \cdot 1^{-1}\right)$ & $0.44(0.04)$ & $0.45(0.03)$ & $0.45(0.05)$ & $0.47(0.03)$ & $0.46(0.03)$ \\
\hline Supine HR (beats $\cdot \min ^{-1}$ ) & $41 \quad(2)$ & $42 \quad(3)$ & $41 \quad(2)$ & $43 \quad(2)$ & $42 \quad(3)$ \\
\hline MABP (mmHg) & $91 \quad(10)$ & $85 \quad(7)$ & $88 \quad(8)$ & $96 \quad(10)$ & $90 \quad(7)$ \\
\hline $\operatorname{MVV}\left(1 \cdot \min ^{-1}\right)$ & $159 \quad(35)$ & $172(37)$ & $158(39)$ & $180(34)$ & 185 (33) \\
\hline
\end{tabular}

${ }^{a}$ ALT test which represents mean values obtained between days 8 and 19 at 1500-2000 m above sea-level

Table 3 Resting cardiorespiratory and haematologic data at sea-level and altitude. (POST 1 Ten-days post-altitude test, $P O S T_{2} 20$ days post-altitude test, $E X P_{M A X}$ experimental maximal exercise group, $C O N_{M A X}$ control maximal exercise group)

\begin{tabular}{|c|c|c|c|c|c|c|}
\hline & \multicolumn{4}{|l|}{$\mathrm{EXP}_{\mathrm{MAX}}$} & \multicolumn{2}{|l|}{$\mathrm{CON}_{\mathrm{MAX}}$} \\
\hline Serum urea $\left(\mathrm{mmol} \cdot \mathrm{l}^{-1}\right)$ & $4.59(1.45)$ & $5.48(0.51)$ & $5.67(1.38)$ & $4.97(0.72)$ & $5.65(1.37)$ & $6.12(1.17)$ \\
\hline $\mathrm{Hb}\left(\mathrm{g} \cdot \mathrm{dl}^{-1}\right)$ & $15.0(1.1)$ & $15.7(1.0)$ & $16.3(0.87)$ & $15.7(1.2)$ & $15.0(0.9)$ & $15.0(1.2)$ \\
\hline $\operatorname{PCV}\left(1 \cdot 1^{-1}\right)$ & $0.47(0.04)$ & $0.47(0.03)$ & $0.48(0.02)$ & $0.46(0.03)$ & $0.48(0.03)$ & $0.49(0.03)$ \\
\hline Supine HR (beats $\cdot \min ^{-1}$ ) & $53 \quad(6)$ & $48 \quad(4)^{* *}$ & $49(6)^{*}$ & $56 \quad(6)$ & $50 \quad(5)$ & $53 \quad(8)$ \\
\hline Urine osmolarity (mOsm) & $386(193)$ & $598(151)$ & $746(274)$ & $580(316)$ & $761 \quad(332)$ & $614(267)$ \\
\hline $\mathrm{FEF}_{25-75 \%}\left(1 \cdot \mathrm{min}^{-1}\right)$ & $4.59(1.36)$ & $4.62(1.41)$ & $4.60(1.25)$ & $4.40(1.41)$ & $4.16(1.12)$ & $4.09(1.10)$ \\
\hline $\operatorname{MVV}\left(1 \cdot \min ^{-1}\right)$ & $179(38)$ & $193(39)$ & 187 (19) & $176(39)$ & $156(39)$ & $165(39)$ \\
\hline
\end{tabular}

* Different from within group PRE value, $P<0.05$

** Different from within group PRE value, $P<0.01$

${ }^{a}$ ALT test which represents mean values obtained between days 15 and 27 at $1640 \mathrm{~m}$ above sea-level

Table 4 Haematinic data at sea-level. Reference values: iron, 9.0$29.0 \mu \mathrm{mol} \cdot \mathrm{1}^{-1}$; transferrin, $1.7-3.4 \mathrm{~g} \cdot 1^{-1}$; vitamin $\mathrm{B}_{12}, 180$ $1132 \mathrm{pg} \cdot \mathrm{ml}^{-1}$; red cell folate, $125-600 \mu \mathrm{g} \cdot \mathrm{1}^{-1}$; serum ferritin for males, $20-300 \mathrm{ng} \cdot \mathrm{ml}^{-1}$; serum ferritin for females, $10-$
$300 \mathrm{ng} \cdot \mathrm{ml}^{-1}$. (PRE EXP Pre-altitude experimental group test, $P_{2 S T_{2}}$ EXP 20 days post-altitude experimental group test, $P R E$ $\mathrm{CON}$ pre-altitude control group test, $\mathrm{POST}_{2} \mathrm{CON} 20$ days postaltitude control group test)

\begin{tabular}{llllll}
\hline $\begin{array}{l}\text { Timing/ } \\
\text { Group }\end{array}$ & $\begin{array}{l}\text { Iron } \\
\left(\mu \mathrm{mol} \cdot \mathrm{l}^{-1}\right)\end{array}$ & $\begin{array}{l}\text { Transferrin } \\
\left(\mathrm{g} \cdot \mathrm{l}^{-1}\right)\end{array}$ & $\begin{array}{l}\text { Vitamin B } \\
\left(\mathrm{pg} \cdot \mathrm{ml}^{-1}\right)\end{array}$ & $\begin{array}{l}\text { Red cell } \\
\text { folate }\left(\mu \mathrm{g} \cdot \mathrm{l}^{-1}\right)\end{array}$ & $\begin{array}{l}\text { Ferritin } \\
\left(\mathrm{ng} \cdot \mathrm{ml}^{-1}\right)\end{array}$ \\
\hline PRE EXP $_{\text {POST }_{2} \text { EXP }}$ & $22.8(3.7)$ & $2.9(0.3)$ & $574(171)$ & $436(117)$ & $48(35)$ \\
PRE CON $_{\text {POST }_{2} \text { CON }}^{24.5(4.8)}$ & $26.4(11.0)$ & $2.9(0.2)$ & $495(20)$ & $372(22)$ & $46(20)$ \\
\hline
\end{tabular}

* Different from within group PRE value, $P<0.05$

CON group. A positive Paul-Bunnell blood test indicated that two male subjects had contracted infectious mononucleosis 14 days following their return to sea-level (Bailey and Davies 1997). Whilst the EXP group mean resting leucocyte and neutrophil counts increased after 19 days at altitude $(P<0.05$ vs PRE) plasma glutamine concentration decreased by $143(74) \mu \mathrm{M}(P<0.001$ vs PRE). The greatest decrease in resting plasma glutamine concentration was noted in two Commonwealth med- allists who complained of fatigue and extreme tiredness $[-250 \mu \mathrm{M}$ vs a group mean of $-112(40) \mu \mathrm{M}]$.

\section{Study 1: Submaximal test}

The mean $\left[\mathrm{La}^{-}\right]_{\mathrm{B}}$ concentration decreased by $0.63 \mathrm{mmol} \cdot 1^{-1}(P<0.05 \mathrm{vs}$ PRE) for the EXP group only following their return to sea-level (Table 5). Run- 
Fig. 1 Pooled data representing the incidence of infectious illness at sea-level and during two altitude sojourns (1500$1640 \mathrm{~m})$. A1-A28 represent days spent at $1500-1640 \mathrm{~m}$.

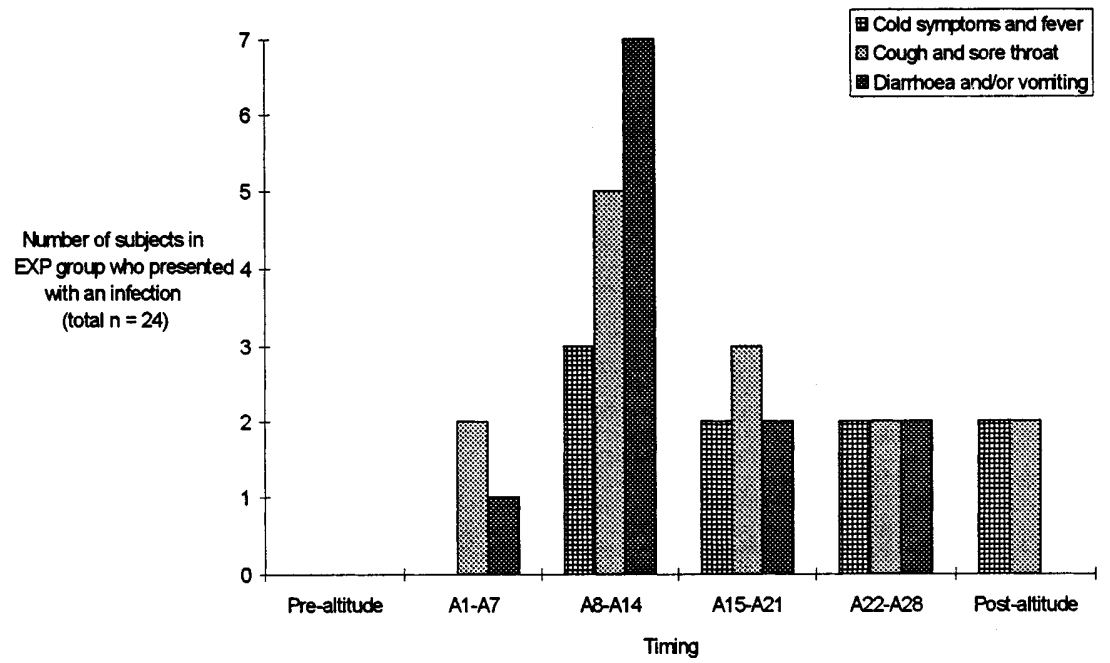

ning velocity at $2 \mathrm{mmol} \cdot 1^{-1}\left[\mathrm{La}^{-}\right]_{\mathrm{B}}$ and $4 \mathrm{mmol} \cdot 1^{-1}$ $\left[\mathrm{La}^{-}\right]_{\mathrm{B}}$ increased by $9 \% \quad(P<0.05)$ and $12 \%$ $(P<0.05)$, respectively in the EXP group, whilst no changes were observed in CON group mean values. However, the reduced lactic acidosis was not associated with any significant changes in the $\theta\left[\mathrm{La}^{-}\right]_{\mathrm{B}}$ value, thus it was apparent that the exponential increase in $\left[\mathrm{La}^{-}\right]_{\mathrm{B}} \mathrm{Oc}-$ curred at the same absolute running velocity. Hypobaric hypoxia did not affect the cardiorespiratory response to submaximal exercise following return to sea-level.

\section{Study 2: Maximal test}

Table 6 demonstrates that the EXP group mean $\dot{V} \mathrm{O}_{2 \max }$ decreased by $13 \%$ after 20 days at altitude $(P<0.05$ vs PRE) and that arterial oxygen saturation decreased to $82(5) \%$ despite a $75.11 \cdot \mathrm{min}^{-1}$ increase in minute ventilation $P<0.01$ vs PRE). Maximal HR and run-

Table 5 Metabolic and cardiorespiratory responses to a standardised submaximal treadmill test. [[ $\left.\mathrm{La}^{-}\right]_{\mathrm{B}}$ Whole blood lactate concentration; $V_{2 \mathrm{mmol} \cdot 1^{-1}}$, interpolated running velocity at $2 \mathrm{mmol} \cdot \mathrm{1}^{-1}\left[\mathrm{La}^{-}\right]_{\mathrm{B}}, V_{4 \mathrm{mmol} \cdot \mathrm{1}^{-1}}$ interpolated running velocity at $4 \mathrm{mmol} \cdot \mathrm{l}^{-1}\left[\mathrm{La}^{-}\right]_{\mathrm{B}}, r^{2}$ co-efficient of determination of exponential ning time to exhaustion also decreased by 12 beats $\min ^{-1}(P<0.01$ vs PRE $)$ and $122 \mathrm{~s}(P<0.05$ vs PRE $)$, respectively. There were no metabolic or cardiorespiratory changes observed following either 10 or 20 days return to sea-level.

\section{Supramaximal exercise performance}

Ambient temperature, relative humidity and wind velocity were comparable at sea-level and altitude. The metabolic and cardiovascular responses observed during and following recovery from supramaximal exercise were not altered by chronic hypoxia (Tables 7 and 8). However, mean running velocity decreased by $3 \%$ at $1,500 \mathrm{~m}$ and $4 \%$ at $1,640 \mathrm{~m}(P<0.05$ vs PRE $)$ and remained $0.13 \mathrm{~m} \cdot \mathrm{s}^{-1}$ slower following return to sealevel in the altitude-trained group only $(P<0.05$ vs PRE). equation during curve fitting procedure, $\theta\left[\mathrm{La}^{-}\right]_{B}$ lactate threshold (according to the $\mathrm{D}_{\max }$ method of Cheng et al. 1992), RPE ratings of perceived exertion, $\dot{V} \mathrm{O}_{2}$ oxygen uptake (STPD), $\dot{V}_{\mathrm{E}}$ minute ventilation (BTPS), $\dot{V}_{\mathrm{E}} / \dot{V} \mathrm{O}_{2}$, ventilatory equivalent for oxygen (BTPS), respiratory exchange ratio (STPD)]

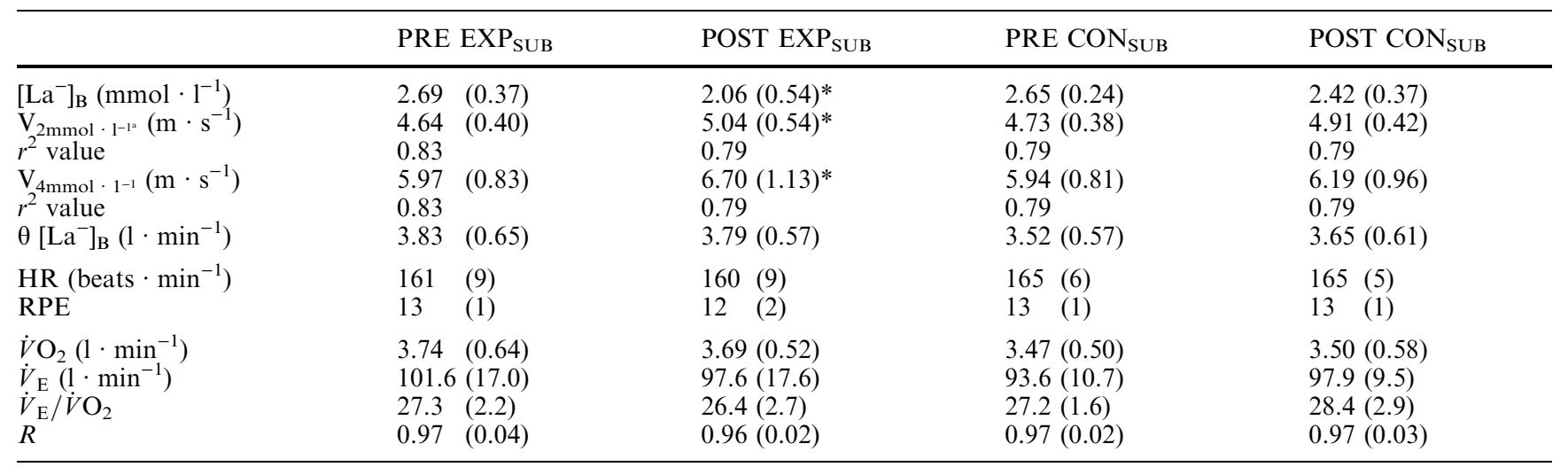

* Different from within group PRE value, $P<0.05$ 
Table 6 Metabolic and cardiorespiratory responses during maximal exercise at sea-level and altitude

\begin{tabular}{|c|c|c|c|c|c|}
\hline Group/Timing & $\begin{array}{l}{\left[\mathrm{La}^{-}\right]_{\mathrm{B}}} \\
\left(\mathrm{mmol} \cdot \mathrm{l}^{-1}\right)\end{array}$ & $\begin{array}{l}\text { HR } \\
\text { (beats } \cdot \min ^{-1} \text { ) }\end{array}$ & $\begin{array}{l}\dot{V} \mathrm{O}_{2} \\
\left(1 \cdot \min ^{-1}\right)\end{array}$ & $\begin{array}{l}\dot{V}_{\mathrm{E}} \\
\left(1 \cdot \min ^{-1}\right)\end{array}$ & $\begin{array}{l}\text { Endurance } \\
\text { Time (s) }\end{array}$ \\
\hline PRE EXP ${ }_{\text {MAX }}$ & $6.08(1.84)$ & $187(8)$ & $5.15(0.95)$ & $177.2(25.3)$ & $485(23)$ \\
\hline $\mathrm{POST}_{1} \mathrm{EXP}_{\text {MAX }}$ & $6.79(0.39)$ & $191(7)$ & $5.21(0.67)$ & $165.0(31.5)$ & $460(19)$ \\
\hline $\mathrm{POST}_{2} \mathrm{EXP}_{\text {MAX }}$ & $7.24(2.76)$ & $190(6)$ & $5.10(0.59)$ & $174.6(17.6)$ & $475(31)$ \\
\hline PRE CON ${ }_{\text {MAX }}$ & $6.29(0.95)$ & $189(12)$ & $4.43(0.95)$ & $142.3(26.5)$ & $539(105)$ \\
\hline $\mathrm{POST}_{2} \mathrm{CON}_{\mathrm{MAX}}$ & $6.99(1.33)$ & $184(11)$ & $4.43(0.86)$ & $147.8(27.1)$ & $501(99)$ \\
\hline
\end{tabular}

* Different from within group PRE value, $P<0.05$

** Different from within group PRE value, $P<0.01$

${ }^{a}$ ALT test which represents mean values obtained between days 19 and 20 at $1640 \mathrm{~m}$ above sea-level

Table 7 Physiological responses during supramaximal exercise

\begin{tabular}{|c|c|c|c|c|c|}
\hline & \multicolumn{3}{|l|}{ EXP } & \multicolumn{2}{|l|}{$\mathrm{CON}$} \\
\hline$\left[\mathrm{La}^{-}\right]_{\mathrm{B}}\left(\mathrm{mmol} \cdot 1^{-1}\right)$ & $7.05(1.49)$ & $6.57(0.96)$ & $6.82(0.62)$ & $6.58(0.62)$ & $5.99(0.84)$ \\
\hline Repetition HR (beats $\cdot \mathrm{min}^{-1}$ ) & $172(5)$ & $170(7)$ & $174(3)$ & $185(3)$ & $183(1)$ \\
\hline Recovery HR (beats $\cdot \min ^{-1}$ ) & $166(1)$ & $165(9)$ & $166(7)$ & $181(3)$ & $174(6)$ \\
\hline RPE & $16(2)$ & $17(2)$ & $16(2)$ & $15(2)$ & $15(1)$ \\
\hline Running velocity $\left(\mathrm{m} \cdot \mathrm{s}^{-1}\right)$ & $5.67(0.50)$ & $5.52(0.51)^{*}$ & $5.69(0.55)$ & $5.62(0.60)$ & $5.62(0.69)$ \\
\hline
\end{tabular}

* Different from within group PRE value, $P<0.05$

${ }^{a}$ ALT test conducted on day 16 at $1500 \mathrm{~m}$ above sea-level

Table 8 Physiological responses during supramaximal exercise

\begin{tabular}{|c|c|c|c|c|c|}
\hline & \multicolumn{3}{|l|}{ EXP } & \multicolumn{2}{|l|}{$\mathrm{CON}$} \\
\hline Repetition HR (beats $\cdot \min ^{-1}$ ) & $181(10)$ & $178(6)$ & $185(8)$ & $181(10)$ & $181(10)$ \\
\hline Recovery HR (beats $\cdot \min ^{-1}$ ) & $138(10)$ & $134(20)$ & $138(9)$ & $127(11)$ & $129(11)$ \\
\hline RPE & $14(1)$ & $17(0)$ & $16(2)$ & $14(1)$ & $15(2)^{*}$ \\
\hline Running velocity $\left(\mathrm{m} \cdot \mathrm{s}^{-1}\right)$ & $5.79(0.10)$ & $5.55(0.13) * *$ & $5.67(0.09) *$ & $5.63(0.55)$ & $5.63(0.50)$ \\
\hline
\end{tabular}

* Different from within group PRE value, $P<0.05$

** Different from within group PRE value, $P<0.01$

${ }^{a}$ ALT test conducted on day 18 at $1640 \mathrm{~m}$ above sea-level

\section{Discussion}

Immune function at altitude

Hypobaric hypoxia causes some adverse changes in immune function, possibly due to the immunomodulatory roles of endogenous glucocorticoids and neuropeptides which increase at altitude (Meehan 1987). The marked increase in the frequency of upper respiratory and gastrointestinal tract infections observed during the altitude sojourn suggest an association between hypobaric hypoxia and the depression of normal immunoreactivity. Whilst communal living may have contributed to the higher incidence of infectious illness at altitude, there were no reports of any physical symptoms for subjects in the CON group, despite identical living and training conditions. All subjects prepared their own food at sea-level and at altitude using identical brands which also suggests that the risk of pathogenic invasion due to the ingestion of foreign foods was minimal. Of the subjects who contracted an infectious illness, two males were diagnosed with infectious mononucleosis on their return to sea-level. The onset of physical symptoms that are characteristic of the first 3-5 days of the prodrome suggested that these subjects were exposed to the Epstein-Barr virus during the initial stages of altitude acclimatisation.

In light of the importance of glutamine as a substrate for macrophages and lymphocytes, Newsholme et al. (1985) suggested that a decrease in the concentration of plasma glutamine below a physiological range would impair defence mechanisms against opportunistic infections. Thus, the decrease in resting plasma glutamine 
concentration observed on day 19 at altitude during this study may have contributed to the apparent depression of normal immune function. Glutamine uptake is required by the kidney to maintain acid-base balance (Goldstein et al. 1980) and increased metabolic acidosis mediated by hypoxia would increase the rate of glutamine uptake. Hypoxia may increase the hepatic uptake of glutamine which is a precursor for the production of the antioxidant glutathione (Hong et al. 1992). Hypoxia is associated with an increased production of free radicals (Simon-Schnass 1994; Vasankari et al. 1997) and thus the production of effective free radical scavengers would prove beneficial. Finally, Wagenmakers (1992) suggested that the hyperadrenalinaemia associated with chronic hypoxia would result in a depletion of 2-oxoglutarate which is required for activation of the branched-chain amino acid aminotransferase reaction that ultimately produces glutamine, and hyperadrenalinaemia decreases the rate of glutamine transport out of rat muscle incubated in vitro (Garber et al. 1976).

A modification of an idea by Rowbottom et al. (1996) describes the relationship between ambient $P_{2}$, training load (intensity and duration) and the subsequent risk of infection (Fig. 2). Once a threshold training load is exceeded (depicted as the metabolic crossover point), concentrations of glutamine would decrease below a physiological range and the risk of infection would subsequently increase. A decreased $P_{\mathrm{I}} \mathrm{O}_{2}$ may shift the metabolic crossover point to the left, thus increasing the aperture of the "window of opportunistic infection". Glutamine supplementation at altitude may help to enhance immune function, since glutamine feeding decreases an athlete's susceptibility to developing respiratory infections at sea-level (Castell et al. 1996).

Altitude training and submaximal exercise performance at sea-level

A decreased lactic acidosis was observed during submaximal exercise at sea-level in the group that trained at altitude. Similar findings have been reported at sea-level following 3-10 weeks of training at an ambient $\mathrm{PO}_{2}$ ranging from 93 to $125 \mathrm{mmHg}$ (Asano et al. 1986; Terrados et al. 1988; Bender et al. 1989; Ingjer and Myhre 1992). Bender et al. (1989) identified that a decrease in lactate flux from skeletal muscle to blood was responsible for the decreased lactic acidosis observed in subjects at sea-level following a 3-week exposure to $4,300 \mathrm{~m}$. Several mechanisms may be implicated in the modulation of glycolytic flux in hypoxia which include, hypoxia-induced secondary polycythaemia and the attendant increase in $C_{\mathrm{a}} \mathrm{O}_{2}$ (Berglund 1992), shifts in substrate utilisation towards predominantly $\beta$-oxidation of fatty acids (Beidleman et al. 1994), beneficial alterations in the structural morphology and enzymatic characteristics of skeletal muscle, capillary neoformation (Desplanches et al. 1993), increase in intracellular buffering capacity (Favier et al. 1995) and an "upstream" inhibition of glycolysis regulated by a decreased central drive (Kayser et al. 1994) and/or changes in the $\beta$-adrenergic sensitivity of glycolysis (Brooks et al. 1992). The decreased lactic acidosis appeared to be independent of any apparent increases in $C_{\mathrm{a}} \mathrm{O}_{2}$ or fat oxidation, as noted by a stable $\mathrm{Hb}$ concentration at rest and the respiratory exchange ratio during exercise. However, the fact that the $\theta\left[\mathrm{La}^{-}\right]_{\mathrm{B}}$ and other cardiorespiratory determinants of running economy were unchanged following return to sea-level questions the functional significance of the decreased lactic acidosis.

Altitude training and maximal exercise performance at sea-level

Chronic hypoxia did not influence performance either during or following recovery from maximal exercise after 10 or 20 days return to sea-level. These findings are consistent with the majority of controlled investigations that have induced hypobaric or normobaric hypoxia either as an intermittent (Hahn et al. 1992; Desplanches et al. 1993; Favier et al. 1995) or continuous stimulus
Fig. 2 Hypothetical model describing the relationship between training load, ambient partial pressure of oxygen $\left(\mathrm{PO}_{2}\right)$ and plasma glutamine concentration (dashed line) and risk of developing an infectious illness (solid line). ( $X$ Metabolic crossover point)

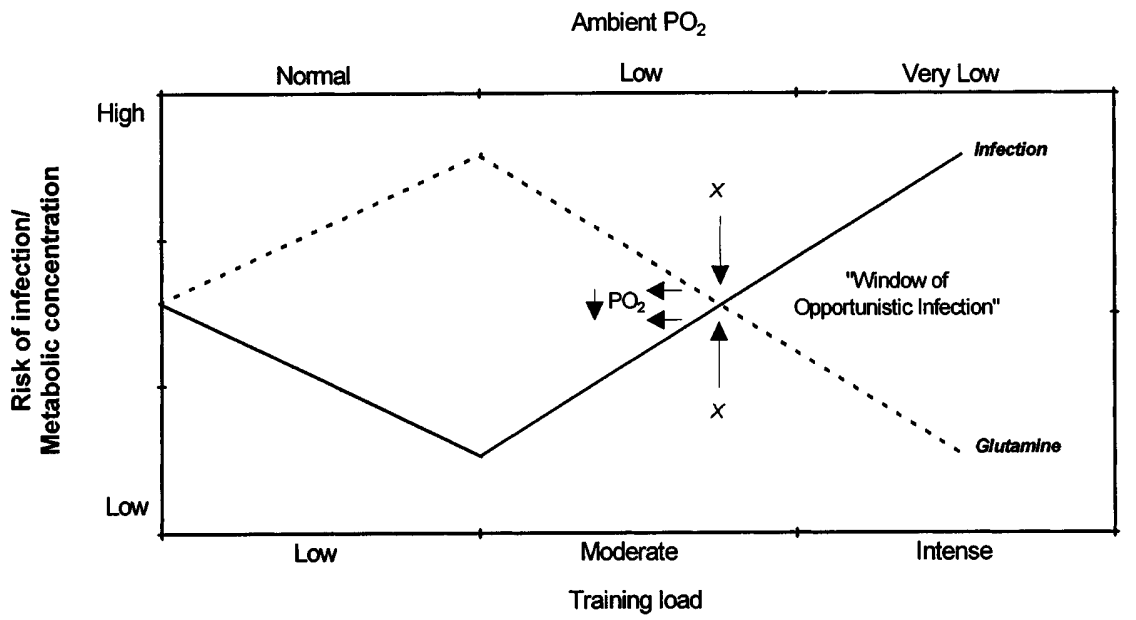


(Svedenhag et al. 1991; Rusko et al. 1996; Telford et al. 1996).

The present hypoxic stimulus was not sufficient to increase blood reticulocyte count and subsequent $\mathrm{Hb}$ concentration and, as a consequence, $C_{\mathrm{a}} \mathrm{O}_{2}$ most probably did not change. The prevalence of iron deficiency in the EXP group despite daily enteral iron supplementation may have suppressed haematological adaptation. Logistical limitations precluded the administration of parenteral iron treatment prior to the altitude sojourn to normalise subject iron stores. Iron demand and mobilisation increases markedly during hypoxia to support the elevated reticulocytosis (Reynfarje et al. 1959) and thus the already depleted iron stores at sea-level may have proved insufficient to meet the increased demand for $\mathrm{Hb}$ synthesis at altitude.

Altitude training and supramaximal exercise performance at sea-level

Whilst aerobic metabolism is the predominant means of removing $\left[\mathrm{La}^{-}\right]_{\mathrm{B}}$ and replenishing ATP and creatine phosphate stores during recovery from supramaximal exercise ( $>\dot{V} \mathrm{O}_{2 \max }$ ), the provision of energy during the $1000-\mathrm{m}$ track repetitions would require a significant contribution from anaerobic metabolism. Chronic exposure to environmental hypoxia improves anaerobic metabolism, due predominantly to an increase in muscle buffer capacity and the associated improvements in acidbase status (Mizuno et al. 1990; Svedenhag et al. 1991; Favier et al. 1995; Nummella et al. 1996). Elevated muscle lactate and $\mathrm{H}^{+}$concentration, in addition to a compensatory respiratory alkalosis during the early stages of altitude acclimatisation result in a greater decrease in $\mathrm{pH}$ per $\mathrm{mmol} \mathrm{H}^{+}$release (West 1986). The increased buffer capacity at altitude may therefore serve as an adaptive mechanism which attenuates the degree of acidosis (Svedenhag et al. 1991).

Chronic exposure to hypobaric hypoxia impaired supramaximal exercise performance 20 days following return to sea-level. Group mean running velocity decreased by $2 \%$ in the altitude-trained group. This response appeared to be independent of any changes in training load, environmental conditions and subject motivation. A decrease in absolute training intensity due to an alveolar-end-capillary diffusion limitation and/or the performance debilitating effects of subclinical infections mediated by the immunosuppressive effects of hypoxia may have been implicated in this response.

\section{Conclusion}

Two investigations demonstrated that 4 weeks of moderate altitude training at $1500-2000 \mathrm{~m}$ did not improve performance during and following recovery from either submaximal or maximal exercise. Chronic hypoxia im- paired supramaximal exercise performance following return to sea-level. A decrease in absolute training intensity at altitude and a marked increase in the incidence of infectious illness, possibly due to a decrease in resting plasma glutamine concentration, may be implicated in these responses.

Acknowledgements The authors would like to extend their thanks to the following scientists for their contributions: Dr R. Robergs of the University of New Mexico, USA, Dr R. Carter of Witwatersrand Medical School, Johannesburg, South Africa, K. Lee of Cardiokinetics, UK, J. Griffin of the British Olympic Association, London, UK, R. Godfrey and S. Humphreys of the British Olympic Medical Centre, London, UK, S. Newport of Loughborough University, Loughborough, UK, and Mr T. Ashton of the University of Glamorgan, Pontypridd, UK. These studies were funded by grants from the British Olympic Association and the British Athletics Federation.

\section{References}

Altman DG (1980) Statistics and ethics in medical research. How large a sample? Br Med J 281:1336-1338

Altman DG (1991) Practical Statistics for Medical Research. Chapman Hall, London, pp 171-173

Asano K, Sub S, Matsuzaka A, Hirakoba K, Nagai J, Kawaoka T (1986) The influences of simulated high altitude training on work capacity and performance in middle and long distance runners. Bull Inst Health Sports Sci 9:195-202

Bailey DM, Davies B (1997) Physiological implications of altitude training for endurance performance at sea-level - A review, Br J Sports Med 31:183-190

Bailey DM, Davies B, Budgett R, Gandy G (1997) Recovery from infectious mononucleosis following altitude training in an elite middle distance runner. Br J Sports Med 31:153-154

Beidleman BA, Muza SR, Fulco CS, Rock PB, Lyons T, Hoyt RW, Cymerman A (1994) Decreased lactate accumulation following acclimatization to $4300 \mathrm{~m}$ is retained after eight days at sea level (abstract). Med Sci Sports Exerc 26:118

Bender PR, Groves BM, McCullough RE, McCullough RG, Trad L, Young AJ, Cymerman A, Reeves JT (1989) Decreased exercise muscle lactate release after high altitude acclimatization. J Appl Physiol 67:1456-1462

Berglund B (1992) High-altitude training. Aspects of haematological adaptation. Sports Med 14:289-303

Borg G (1973) Perceived exertion; a note on history and methods. Med Sci Sports Exerc 5:90-93

Boutellier U, Marconi C, diPrampero PE, Cerretelli P (1982) Effects of chronic hypoxia on maximal performance. Clin Respir Physiol 18:39-44

Brooks GA, Wolfel EE, Groves BM, Bender PR, Butterfield GE (1992) Muscle accounts for glucose disposal but not blood lactate appearance during exercise after acclimatization to 4300 m. J Appl Physiol 72:2435-2445

Castell LM, Poortmans JR, Newsholme EA (1996) Does glutamine have a role in reducing infections in athletes? Eur $\mathbf{J}$ Appl Physiol 73:488-490

Cheng B, Kuipers H, Snyder AC, Keizer HA, Jeukendrup A, Hesselink M (1992) A new approach for the determination of ventilatory and lactate thresholds. Int J Sports Med 13:518-522

Desplanches D, Hoppeler H, Linoissier MT, Denis C, Claassen H, Dormois D, Lacour JR, Geyssant A (1993) Effects of training in normoxia and normobaric hypoxia on human muscle ultrastructure. Pflugers Arch 425:263-267

Favier R, Spielvogel D, Desplanches D, Ferretti G, Kayser B, Grunenfelder A, Leuenberger M, Tuscher L, Cacares E, Hoppeler H (1995) Training in hypoxia vs. training in normoxia in high-altitude natives. J Appl Physiol 78:2286-2293 
Garber AJ, Karl IE, Kipnis DM (1976) Alanine and glutamine synthesis and release from skeletal muscle. IV. beta-adrenergic inhibition of amino acid release. J Biol Chem 251:851-857

Goldstein L, Schrock H, Cha CJ (1980) Relationship of muscle glutamine production to renal ammonia metabolism. Biochem Soc Trans 8:509-510

Gore CJ, Hahn AG, Watson DB, Norton KI, Campbell DP, Scroop GS, Emonson DL, Wood RJ, Ly SV, Bellenger SJ, Lawton EW (1996) $\dot{V} \mathrm{O}_{2}$ Max and arterial $\mathrm{O}_{2}$ saturation at sealevel and $610 \mathrm{~m}$ (abstract). Med Sci Sports Exerc 27:42

Hahn AG, Telford RD, Tumilty DM, McBride ME, Campbell DP, Kovacic JC, Batschi R, Thompson PA (1992) Effect of supplementary hypoxic training on physiological characteristics and ergometer performance of elite rowers. Excel 8:127-138

Hong RW, Rounds JD, Helton WS, Robinson MK, Wilmore DW (1992) Glutamine preserves liver glutathione after lethal hepatic injury. Ann Surg 215:114-119

Ingjer F, Myhre K (1992) Physiological effects of altitude training on elite male cross-country skiers. J Sports Sci 10:37-47

Kayser B, Narici M, Binzoni T, Grassi B, Cerretelli P (1994) Fatigue and exhaustion in chronic hypobaric hypoxia: influence of exercising muscle mass. J Appl Physiol 76:634-640

Kinnear PR, Gray CD (1994) SPSS for windows. Psychology Press Publishers, East Sussex

Levine BD, Stray-Gundersen J (1997) "Living high-training low": effect of moderate-altitude acclimatization with low-altitude training on performance. J Appl Physiol 83:102-112

Maher JT, Jones LG, Hartley LH (1974) Effects of high altitude exposure on submaximal endurance capacity of men. J Appl Physiol 37:895-898

Mairbaurl H, Schobersberger W, Humpeler E, Hasibeder W, Fischer W, Raas E (1986) Beneficial effects of exercising at moderate altitude on red cell oxygen transport and on exercise performance Pflugers Arch 406:594-599

Meehan RT (1987) Immune supression at high altitude. Ann Emerg Med 16:974-979

Meehan RT, Duncan U, Neale LS, Taylor G, Muchmore H, Scott N, Ramsey K, Smith E, Rock P, Goldblum R, Houston C (1988) Operation Everest 2: alterations in the immune system at high altitudes. J Clin Immunol 8:397-406

Mizuno M, Juel C, Bro-Rasmussen T, Mygind E, Schibye B, Rasmussen B, Saltin B (1990) Limb skeletal muscle adaptation in athletes after training at altitude. J Appl Physiol 68:496-502

Newsholme EA, Crabtree B, Ardawi MSM (1985) Glutamine metabolism in lymphocytes: its biochemical, physiological and clinical importance. Q J Exp Physiol 70:473-489

Nieman DC (1996) Effect of long-term training on the immune system and on resistance to infectious diseases. In: Maughan RJ, Shirereffs SM (eds) Biochemistry of exercise IX. Human Kinetics, Champaign, Illinois, pp 383-398

Nummela A, Jouste P, Rusko H (1996) Effect of living high and training low on sea level anaerobic performance in runners (abstract). Med Sci Sports Exerc 28:740

Pronk NP (1993) Short term effects of exercise on plasma lipids and lipoproteins in humans. Sports Med 16:431-448
Pugh LGCE (1967) Athletes at altitude. J Physiol (Lond) 192:619646

Reynafarje C, Lozano R, Valdivieso J (1959) The polycythemia of high altitudes: iron metabolism and related aspects. Blood 14:433-455

Rowbottom DG, Keast D, Morton A (1996) The emerging role of glutamine as an indicator of exercise stress and overtraining. Sports Med 21:80-97

Rusko HK, Kirvesniemi H, Paavolainen L, Vahasoyrinki P, Kyro KP (1996) Effect of altitude training on sea level aerobic and anaerobic power of elite athletes (abstract). Med Sci Sports Exerc 28:739

Simon-Schnass I (1994) Risk of oxidative stress during exercise at high altitude. In: Sen CK, Packer L, Hanninen O (eds) Exercise and oxygen toxicity. Elsevier Amsterdam pp 191-210

Svedenhag J, Saltin B, Johansson C, Kaijser L (1991) Aerobic and anaerobic exercise capacities of elite middle-distance runners after two weeks of training at moderate altitude. Scand J Med Sci Sports 1:205-214

Taylor HL, Buskirk E, Henschel A (1955) Maximal oxygen intake as an objective measure of cardio-respiratory performance. $\mathbf{J}$ Appl Physiol 8:73-80

Telford RD, Graham KS, Sutton JR, Hahn AG, Campbell DA, Creighton SW, Cunningham RB, Davis PG, Gore CJ, Smith JA, Tumilty DMcA (1996) Medium altitude training and sealevel performance (abstract). Med Sci Sports Exerc 28:741

Terrados N, Melichna J, Sylven C, Jansson E and Kaijser L (1988) Effects of training at simulated altitude on performance and muscle metabolic capacity in competitive road cyclists. Eur $\mathbf{J}$ Appl Physiol 57:203-209

Terrados N, Jansson E, Sylven C, Kaijser L (1990) Is hypoxia a stimulus for synthesis of oxidative enzymes and myoglobin? $\mathbf{J}$ Appl Physiol 68:2369-2372

Vasankari TJ, Kujala UM, Rusko H, Sarna S, Ahotupa M (1997) The effects of endurance exercise at moderate altitude on serum lipid peroxidation and antioxidative functions in humans. Eur $\mathbf{J}$ Appl Physiol 75:396-399

Wagenmakers AJM (1992) Amino acid metabolism, muscular fatigue and muscle wasting. Speculations on adaptations at high altitude. Int J Sports Med 13:S110-S113

Welch HG (1987) Effects of hypoxia and hyperoxia on human performance. Exerc Sports Sci Rev 15:191-221

West JB (1986) Lactate during exercise at extreme altitude. Fed Proc 45:2953-2957

Windmueller HG and Spaeth AE (1974) Uptake and metabolism of plasma glutamine by the small intestine. J Biol Chem 249:50705079

Wolfel EE, Groves BM, Brooks GA, Butterfield GE, Mazzeo RS, Moore LG, Sutton JR, Bender PR, Dahms TE, McCullough RE, McCullough RG, Huang SY, Sun SF, Grover RF, Hultgren HN, Reeves JT (1996) Oxygen transport during steady state submaximal exercise in chronic hypoxia. J Appl Physiol 70:1129-1136

Young AJ, Evans WJ, Cymerman A, Pandolf KB, Knapik JJ, Maher JT (1982) Sparing effect of chronic high altitude exposure on muscle glycogen utilisation. J Appl Physiol $52: 857-862$ 